\title{
Anne Leonora Blaakilde and Gabriella Nilsson (eds.) (2013). Nordic Seniors on the Move. Mobility and Migration in Later Life. Lund: Lund Studies in Arts and Cultural Sciences 4, 225 pp. ISBN 9789198145809 (paperback), ISSN 20017510 (online)
}

\author{
ReVIEWed by Sofi FrISTEDT*
}

This is an anthology well-worth reading as it tackles a quite novel phenomenon: seniors on the move. Although some years have passed since its publication, it is still relevant and up to date. All chapters are well written and the quality is augmented by the fact that all texts have passed doubleblind peer reviewing. The book encompasses research from various disciplines that focus on mobility and migration, all using the same method, namely ethnography. Although the authors do not state it explicitly, I consider the book as research in line with the "new mobilities paradigm" that originates from sociology and was developed primarily by British scholars John Urry and Tim Cresswell. This paradigm has been developed in the past 15 years as a response to previous perspectives that failed to acknowledge and recognise intersections between geography (place) and social categories such as class, ethnicity and gender. The paradigm has however been criticised for paying too little attention or even forgetting to add age as a social category of relevance in this situation. Based on this

* Sofi Fristedt, Department of Rehabilitation, School of Health and Welfare, Jönköping University, Sweden 
International Journal of Ageing and Later Life

critique, an anthology like this one focusing on age is all the more relevant, important and even necessary. What makes this book especially interesting is its focus on the rather novel phenomenon of Nordic seniors moving to leisure areas in their home countries or abroad. A growing number of international publications has also discussed this topic, but scientific texts describing this phenomenon from a Nordic perspective are few. So this anthology clearly adds knowledge to address this gap.

A well-written introduction helps to familiarise the reader to the context and situations that are further developed in the book. We have been informed that the number of seniors making this lifestyle migration have increased considerably over the past 20 years. The authors argue that this rise is potentially due to an increase in mass tourism and also due to better finances among seniors in general. In addition, more people live longer and with better health, which in turn facilitates different and varied ways of growing old as discussed by the authors. As in younger years, travelling and also mobility and migration could provide quality of life in later life as well.

The different chapters of the book highlight various aspects of senior mobility and migration, among other things rural retirement migration in Sweden as well as lifestyle motives for moving to senior housing in a Swedish setting. Furthermore, eating habits as well as religious life of Finnish retirement migrants in Spain are described in two separate chapters. In the two following chapters, perspectives on the Church of Sweden abroad as "like coming home" and transnational voluntarism for Swedish senior migrants are in focus. Finally, the challenge of (Danish or other EU) welfare states' policies when it comes to retirement migration and national health promotion are introduced as also the mobilities of third agers.

To summarise, it becomes clear from the book that mobility and migration may affect many other aspects of human life such as images of ageing, identities, traditions, feelings of belonging ("doing and feeling at home"), friendships and relations with family and other relatives as well as religious attachments. The provided examples based on empiricism give concrete and interesting descriptions from different contexts related to different populations.

But mobility and migration is also wisely problematised in this book as a complex phenomenon. Being on the move is, for example, not only seen as an aspect of being healthy but also as an aspect of staying healthy by 
some seniors mentioned in the book. They have made their migration for the benefit of their own health, seeking for instance a warmer climate in Southern Europe. This may, however, have implications on social welfare policies and thus personal economy, such as reduced pensions from the Nordic home country. It may in fact be that the migrant has to return home and consequently compromise on personal health when doing so. This is an important finding, which deserves to be taken up and debated by policy makers to inform policy and societal planning. It is also surprising and a bit contradictory that activities remain almost the same for many of the individuals described in the book. Although seniors on the move change their surroundings, they re-create routines and thus continue to do more or less the same activities as before.

The book is also well-worth reading to get deeper and wider perspectives on later life and ageing. Migration and mobility are in some situations described as signs of "non-ageing" by the seniors in the presented studies. These perspectives stand somewhat in contrast to traditional views that assume later life to be opposed to mobility. However, given the lifestyle changes and developments in health, it is obviously time to revise and question traditional views of seniors. Sweet old ladies and nice old gentlemen may still exist, but nowadays they sometimes ride a Harley Davidson and experience "a second age of mobility that recall their teenage years," as suggested in the Introduction of this book. For similar reasons, authors throughout the book use the term "seniors", signifying strength and energy, rather than disease and frailty. The two latter concepts are more or less associated with the concept of "old age" in discourse. Striking examples in the anthology point to new ageing processes and provide examples of later life of today that are relevant to spread and discuss, since these are also true pictures of ageing. On the contrary, I would have liked to see a bit more reflection on how this discourse could be problematic for persons who cannot remain healthy, be mobile or migrate.

To summarise, I would really like to recommend reading this book since it rakes up many thoughts, reflections, and provides new insights into important aspects of later life. 